\title{
Assessment of Environmental and Technological Factors over the Mycorrhizal Colonization for the Festuca Rubra Specie in the End of the Vegetation Period
}

\author{
Roxana VIDICAN, Vlad STOIAN*, Ioan ROTAR, Florin PĂCURAR \\ ${ }^{1}$ Faculty of Agriculture. University of Agriculture and Veterinary Medicine Cluj, 3-5 Calea Mănăștur str., \\ 400372, Cluj-Napoca, Romania. \\ * corresponding author: vlad.stoian@usamvcluj.ro
}

Bulletin USAMV series Agriculture 71(2)/2014

Print ISSN 1843-5246; Electronic ISSN 1843-5386

DOI 10.15835/buasvmcn-agr: 10845

\begin{abstract}
Mycorrhizal fungi constitutes a critical component of ecosystems, and through the involvement in the absorption and transfer, they have the ability to adjust the permanent and cyclical movement of nutrients in the entire ecosystem. Mycorrhizas have the ability to decrease inputs introduced into ecosystems, but allocation of ecosystem nutrient resources only to symbiotic plants may cause, in time, the destabilization of plant communities. Objectives of the study were to create a hierarchy of climatic factors (temperature and rainfall) and technological (fertilization + treatment) depending on the power to influence the mycorrhizal development. Analysis of colonization parameters variation is conducted using data collected from a field experiment, over which were applied mineral and organic fertilizers under treatment with fungicides and zinc sulphate. Exploration of experimental data using cluster analysis revealed a good segmentation of variants fertilized and treated, based on the values of frequency and intensity of colonization in the root system of Festuca rubra plants. Temperature and rainfall had a significant influence within the study period on the level of root colonization. Treatment with fungicide and zinc sulphate acted individually with a less pronounced effect, but more restrictive, the separation between clusters being made on the axis of treatments. Ecological factors determine the division of experimental variants in clusters defined by the ranges of colonization parameters, and by overlapping balanced fertilization completed with treatments over climate, the percentage of colonization frequency rises to maximum, individual expression of technological factors being optimal.
\end{abstract}

Keywords mycorrhiza, fertilization, fungicide, zinc sulphate, climate

\section{INTRODUCTION}

Matured ecosystems are cauterized by the existence of a mycorrhizal hyphal network, capable of interconnecting the radicular systems of plants. Most common associations of roots and fungi are vesicular - arbuscular, the major fungi contribution being identified within the absorption process of nutritive elements. Particularly this is identified in soil sequences that the plant is unable to explore.

Mycorrhizal fungi's, once involved in the absorption and transfer processes, have the ability to adjust the permanent and cyclical motion of the nutritive elements in the entire ecosystem. At a superior level, the composition and functionality of plant's communities is controlled, the food sources allocation process being accomplished through hyphal networks developed by the symbiotic fungus.

In agricultural soils, the vesicular - arbuscular fungi represent a $35-76 \%$ from the total microbial biomass, percentage which converts the fungi into a critical component of efficient agricultural ecosystems. Through their activity, these may influence the growth and development of plants; enhance the dryness tolerance, or may cause antagonistic effects for disease or pests casese, by protecting the plant's "health" status (Smith and Read, 2008, Tuteja and Gill, 2013, Bompadre et al., 2014).

By optimizing the food resources, mycorrhizas may decrease the inputs within the ecosystem, all 
at once enhancing the obtained results. During time, allocating the nutritional resources from the ecosystem only to the symbiotic plants may lead to unbalanced plant communities. After a certain level of this phenomenon, certain species may face extinction danger, perspective which impacts irrecoverably the biodiversity. One preventative measure against this endangerment is represented by fungicidal treatments applied in order to reduce the colonization and maintain the ecosystem balanced (Sun et al., 2013, Gill et al., 2013).

In relevant cereal cultivation areas, within their biological systems, a Zinc insufficiency phenomenon was noticed. This imprints a decrease of the cultivated plants efficiency to access water resources (Watts-Williams et al., 2014).

The positive correlation between the Zinc level and the water absorption sustains the hypothesis of an efficient agricultural ascension by applying products based on this element. This beneficial influence is expanded also over the mycorrhizal colonization development, by enlarging the water absorption surface.

\section{MATERIALS AND METHODS}

For analyzing the fertilization effect over the mycorrhizal colonization parameters on the Festuca rubra species, an experiment was set comprising of 6 degrees of fertilization, one unfertilized witness (F1), manure fertilized (F2) $10 \mathrm{t} / \mathrm{ha}$, manure supplemented with Nitrogen (F3) - $10 \mathrm{t} / \mathrm{ha}+\mathrm{NPK}=50: 25: 25$, mineral with NPK (F4) - 50:25:25, mineral with Eurofertil mezocalc (F5) - $120 \mathrm{~kg} / \mathrm{ha}+\mathrm{N}=50$; and mineral with Eurofertil mezocalc (F6) - $120 \mathrm{~kg} / \mathrm{ha}$ fertilizations. Each variant was subjected to one single treatment: with fungicide (T1 - Botran $75 \mathrm{Wp}-0.07 \%$ ), or Zinc Sulphate (T2 - 1.0\%).

The study's objectives were to develop a hierarchy of the climatic factors (Temperature - temp; Precipitation - prep) and technological factors (fertilization + treatment); to assess the doses and fertilizer's type effects; and evaluating the parameters fluctuation with the applied treatment.

The experimental concept, experimental field design and data collection methodology were presented by Stoian (2011), additions being made to the statistical analysis level, by underlying the individual effect of experimental factors (Vidican et al., 2013).
The colonization parameters evolution analysis, in fertilization and treatment conditions, has used data obtained during 2010 (A1) and 2011 (A2). The ecological conditions were calculated for the complete vegetation period.

The appreciation of differences between the colonization levels of the experimental variants was made through cluster type analysis. For rating the fertilization, treatment and ecological factors effects over the colonization parameters, a Principal Components Analysis (PCA) was used. For data analysis and graphical projections, the $\mathrm{R}$ Statistic (R Core Team, 2014) - "vegan" package was used (Oksanen et al., 2013)

\section{RESULTS AND DISCUSSION}

Exploring the experimental data through the cluster analysis has determined a sound segmentation of fertilized and treated variants, based on the obtained values for colonization frequency and intensity in the Festuca rubra's radicular system (Fig. 1; Tab. 1). The colonization parameters fluctuation has set a double split of the cluster's dendrogram. After the first split, 2 clusters resulted (A and B), segmentation based on the colonization frequency parameter. For the second segmentation, the frequency values are used for organizing the experimental variants in the graphical model, but the parameter responsible for balancing the dendrogram being the colonization intensity. This resulted in 5 clusters $(1 ; 2 ; 3 ; 4 ; 5)$.

Cluster A reunites the experimental variants with the highest frequency value (Fig. 1; Tab. 1). The colonization percentage of the Festuca rubra's roots ranges between $76.67-100 \%$ values. This highlights the intense instalment of mycorrhizal fungi on the surface of symbiotic plants roots. Among the fertilized variants included in this cluster, the lowest frequency level was registered at the manure fertilized and fungicide treated variant, under the 2010 experimental conditions (A1F2T2). The $76.67 \%$ frequency value was supplemented by an intensity of $2.24 \%$ for the fungi intraradicular installed. By applying treatments and with no fertilization, there is no negative influence over the mycorrhizal colonization. During 2010 the frequency registered over 90\% values for the unfertilized and treated variants (A1F1T1 - 96.67\% and A1F1T2 - 98.89\%), while in 2011 experimental conditions, the colonization 


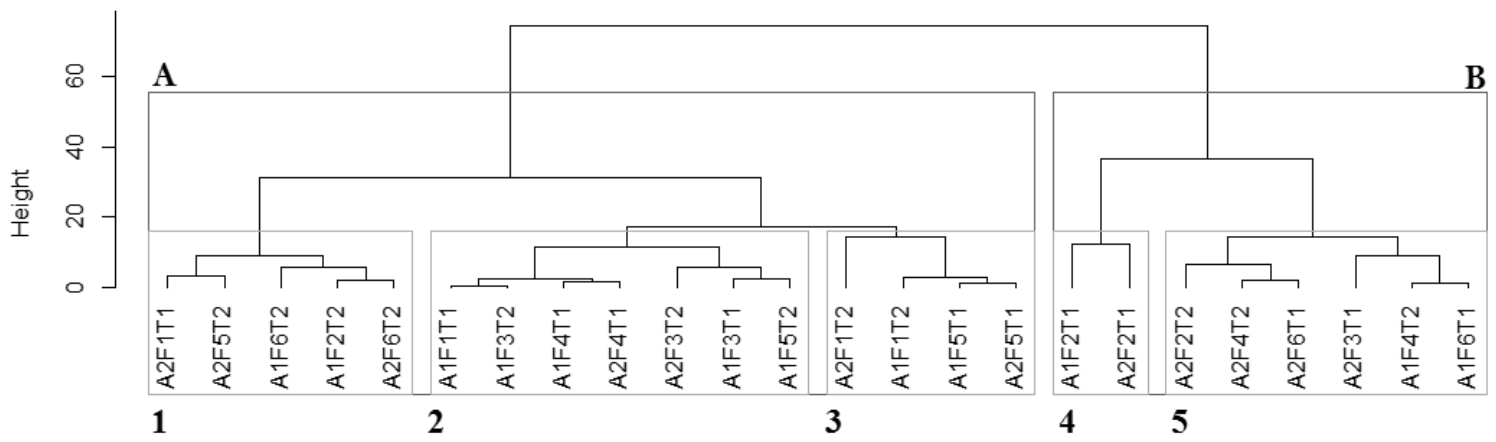

Fig. 1. Fertilization and mulching effect on colonization

Tab. 1. Values of mycorrhizal colonization parameters during the experimental years, by applied fertilization and treatment

\begin{tabular}{|c|c|c|c|c|c|c|c|c|c|}
\hline Fert & Trat & Year & plot & int & freq & Year & plot & int & freq \\
\hline 1 & Zn sulph & \multirow{12}{*}{2010} & A1F1T1 & 13.53 & 96.67 & \multirow{12}{*}{2011} & A2F1T1 & 9.34 & 82.22 \\
\hline 1 & fung & & A1F1T2 & 23.95 & 98.89 & & A2F1T2 & 21.22 & 85.56 \\
\hline 2 & Zn sulph & & A1F2T1 & 0.50 & 41.11 & & A2F2T1 & 0.37 & 28.89 \\
\hline 2 & fung & & A1F2T2 & 2.24 & 76.67 & & A2F2T2 & 1.36 & 51.11 \\
\hline 3 & Zn sulph & & A1F3T1 & 10.59 & 87.78 & & A2F3T1 & 9.76 & 62.22 \\
\hline 3 & fung & & A1F3T2 & 13.77 & 96.67 & & A2F3T2 & 11.40 & 93.33 \\
\hline 4 & Zn sulph & & A1F4T1 & 12.94 & 98.89 & & A2F4T1 & 11.82 & 97.78 \\
\hline 4 & fung & & A1F4T2 & 1.37 & 65.56 & & A2F4T2 & 1.02 & 57.78 \\
\hline 5 & Zn sulph & & A1F5T1 & 22.39 & 100.00 & & A2F5T1 & 21.30 & 100.00 \\
\hline 5 & fung & & A1F5T2 & 9.54 & 90.00 & & A2F5T2 & 8.63 & 78.89 \\
\hline 6 & Zn sulph & & A1F6T1 & 1.85 & 64.44 & & A2F6T1 & 1.09 & 55.56 \\
\hline 6 & fung & & A1F6T2 & 3.57 & 82.22 & & A2F6T2 & 2.12 & 78.89 \\
\hline
\end{tabular}

ranged between $80-90 \%(\mathrm{~A} 2 \mathrm{~F} 1 \mathrm{~T} 1-82.22 \%$ and A2F1T2 - 85.56\%).

The strong segregation between the recorded values, observed for the frequency level, has imposed the framing of all experimental variants with frequency values under $70 \%$ in the B cluster (Fig. 1, Tab. 1). Noticeable is the low value of the colonization frequency for the manure fertilized variant, when treated with fungicide during 2011 (A2F2T2), the 51.11\% frequency being completed by a colonization intensity of just $1.36 \%$.

Cluster B also identifies the combination between unilateral fertilization with NPK superposed to a fungicide treatment, experimental variants from this category (A1F4T2 and A2F4T2) recording low values of the colonization parameters for both experimental years (Fig. 1, Tab. 1). A similar case is noticed for fertilization based on Eurofertil mezocalc and treatment with Zinc Sulphate (A1F6T1 and A2F6T1), the colonization level values being much reduced for this specific combination.

Superposing the fluctuation of the radicular colonization intensity over the intensive segregation of the experimental variants between the 2 clusters has imposed a new split of the dendrogram, the 5 resulting clusters having a higher homogeneity degree of the 2 analyzed parameters (Fig. 1; Tab.1).

Cluster 1 reunites the variants for which the colonization frequency ranged between $76.67 \%$ - 82.22\%; with intensity values from $2.12 \%$ up to $9.34 \%$. This indicates a relatively proper colonization over the installation surface of the mycorrhizal fungi, but shallow colonization when assessing the intra-radicular progress (Fig. 1; Tab. 1). Noticeable is the Eurofertil mezocalc fertilization, combined with a fungicide treatment 
(A1F6T2 and 2F6T2), which, under the ecological conditions of both experimental years, has maintained the frequency level around $80 \%$, and the intensity under 5\%. In 2010, the manure fertilization in combination with a fungicide treatment (A1F2T2) has succeeded raising the colonization frequency at $76.67 \%$ and an intensity of only $2.24 \%$.

In cluster 2, the group comprises of variants with a colonization intensity starting from $9.54 \%$ up to $13.77 \%$ (Fig. 1; Tab.1). These values indicate a superior intra-radicular colonization then the one noticed in cluster 1 . The high frequencies (ranging between 87.78 - 98.89\%) add up for the radicular surface evaluation, on which the mycorrhizal fungi are installed. The low differences between the 2 experimental years of the variants treated with Zinc Sulphate and fertilized with NPK (A1F4T1 and A2F4T1), for both the frequency and intensity parameters, denote the stability of the colonization during time. This is due to the quality of the fertilization - treatment mixture, combined with the ecological conditions of the experimental site. A similar phenomenon is recorded when the analysis is performed on the differences between the variants fertilized with manure supplemented with Nitrogen and treated with fungicide (A1F3T2 and A2F3T2). A very low variation of the colonization parameters was identified between the 2 years.

The highest values of the colonization intensity (over 20\%), added by high values of frequency, have marked cluster 3 with a high degree of homogeneity (Fig. 1; Tab. 1). To be noticed the distinction of the Eurofertil mezocalc fertilisation and Zinc Sulphate treatment (A1F5T1 and $\mathrm{A} 2 \mathrm{~F} 5 \mathrm{~T} 1$ ), which raised the frequency level to $100 \%$ for both experimental years. Applying the fungicide treatment in the absence of fertilization (A1F1T2 and A2F1T2) had a positive effect over the intra-radicular development of the mycorrhizal fungi. High values were recorded for this parameter for both 2010 and 2011.

Combining the manure fertilization with a Zinc Sulphate treatment (A1F2T1 and A2F2T1) has negatively impacted the mycorrhizal colonization (Fig. 1; Tab. 1). The 2 experimental variants were placed in the same cluster 4 , due to their lowest intensity values $(0.50 \%$ and $0.37 \%)$ of the entire experiment.
Cluster 5 contains variants with low colonization intensity while some of the frequencies do not surpass $70 \%$ (Fig. 1; Tab. 1). One noticeable exception is identified for the manure fertilization combined with a Zinc Sulphate treatment (A2F3T1). During 2011's conditions, this variant has recorded a raise up to $9.76 \%$ for the colonization intensity. Establishing this variant within the cluster 5 is based mostly on the $62.22 \%$ value of the frequency, much lower compared with the ones in clusters 1 and 2 , in which the variant could be positioned due to the intensity.

Superposing the experimental factors over the main components analysis chart has highlighted the significant influence that temperature and precipitations had, during the study years, on the radicular colonization level (Fig. 2; Tab. 2). Also notable is the effect that climatic factors have, their position on the ordination chart indicating an antagonised action over the experimental variants. The fungicide and Zinc Sulphate treatments had a les acute individual effect, but much more restrictive for the clusters positioning on the ordination chart. The separation of the clusters was achieved on the treatments axis.

The analysis of the ecological and experimental factors over the variants integrated in cluster 1 has revealed the influences distinguished significant of Phosphorus and significant Potassium (Tab. 3). Superposed with the effect of these 2 chemical elements, the treatments significantly act on the maintenance of a colonization frequency ranging between $76.67-82.22 \%$ (Tab. 1; Tab. 3). For the colonization frequency, the fungicide treatment, in the ecological conditions of 2010, when combined with fertilization based on Eurofertil mezocalc (A1F6T2), had the same effect as the Zinc Sulphate treatment in the absence of fertilization during 2011 climatic conditions (A2F1T1). The recorded value was $82.22 \%$ (Tab. 1). The difference between the 2 variants is noticed at the colonization intensity level. The value for this parameter for the unfertilized variant was 3 times higher than in the fertilized case.

Cluster 2 presents a higher homogeneity for the mycorrhizal colonization parameters, with balanced values for both the frequency and intensity (Fig. 1; Tab. 1). Opposite to this, through the mixture of fertilization and treatment variants within cluster 2 , creating a heterogeneous image. The cluster included the variant organically ferti- 
Tab. 2. Individual effect of experimental factors over the mycorrhizal colonization parameters - at the complete experiment level

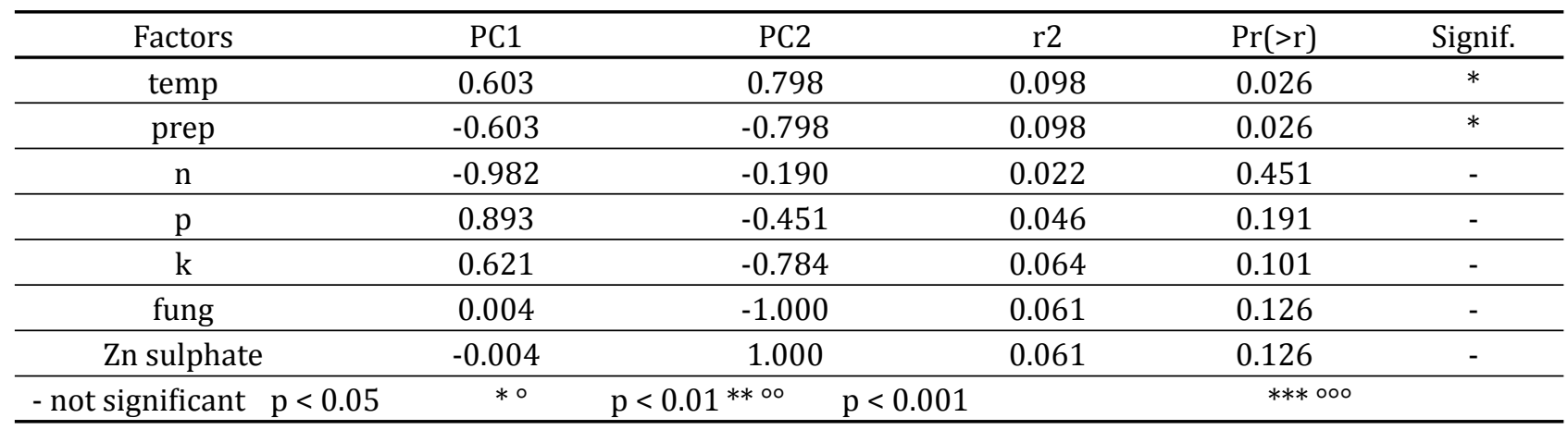

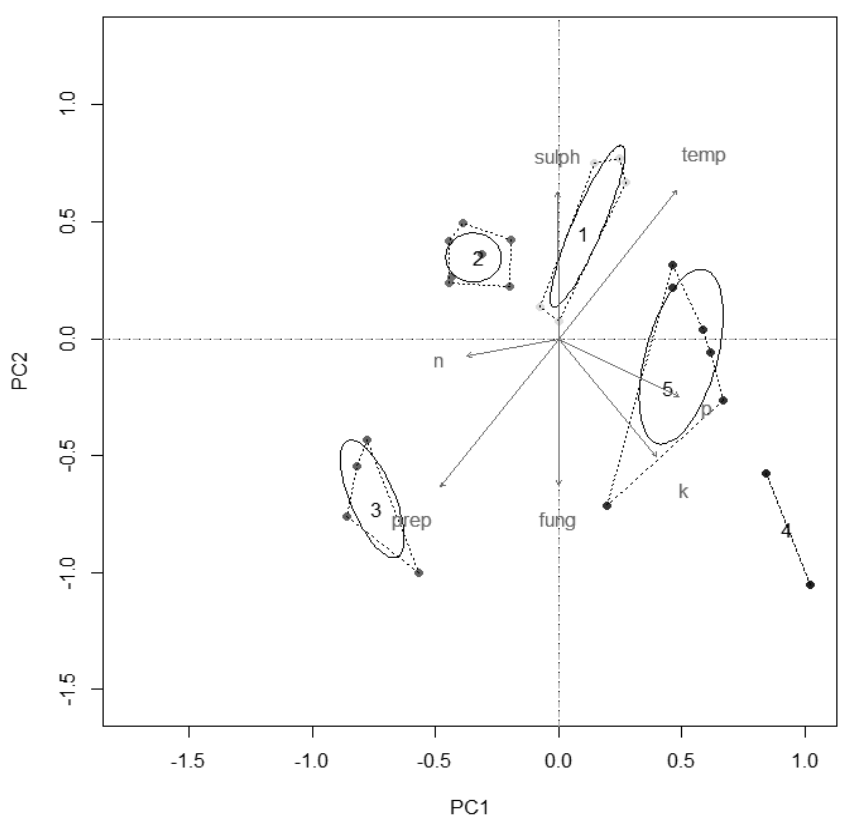

Fig. 2. Analysis of principal components and highlight of the restrictive axis

lized supplemented with Nitrogen; mineral fertilized variant, but also an unfertilized variant. Superposing the experimental factors over the ordering chart has indicated the lack of a significant individual effect. The values obtained for the colonization parameters in cluster 2 deriving from the combined effect of all factors (Tab. 3).

The high values of the colonization parameters recorded by the variants within cluster 3 are owed to the notably balanced individual effect of technological factors (Tab. 1; Tab. 3). Macro-elements are considerably acting over the parameters for the variant fertilized with Eurofertil mezocalc, their influence being added up by the effect of a Zinc Sulphate treatment (F5T1) for both experimental years. The fungicide drove towards the colonisation intensity growth for the unfertilized variant (F1T2), and at the same time raising the frequency's level to over $85 \%$ for both 2010 and 2011.

The manure fertilized variant, treated with Zinc Sulphate (F2T1) has heavily influenced the mycorrhizal colonization during the 2 experimental years. The obtained values allowed the institution of cluster 4 with a reduced dimension (Fig. 1; Tab. 1). The combined effects of fertilization and treatment have not allowed the formulation of the individual impact of the experimental factors (Fig. 2; Tab. 3). 
Tab. 3. Individual effect over the mycorrhizal colonization parameters - cluster levels

\begin{tabular}{|c|c|c|c|c|c|c|c|c|c|c|c|}
\hline \multicolumn{6}{|c|}{ CLUSTER 1} & \multicolumn{6}{|c|}{ CLUSTER 2} \\
\hline Factors & PC1 & PC2 & $\mathrm{r} 2$ & $\operatorname{Pr}(>r)$ & Sig. & Factors & PC1 & PC2 & $\mathrm{r} 2$ & $\operatorname{Pr}(>r)$ & Sig. \\
\hline temp & 0.682 & 0.731 & 0.353 & 0.073 & - & temp & 0.020 & 1.000 & 0.116 & 0.321 & - \\
\hline prep & -0.682 & -0.731 & 0.353 & 0.073 & - & prep & -0.020 & -1.000 & 0.116 & 0.321 & - \\
\hline$n$ & -0.127 & 0.992 & 0.276 & 0.139 & - & $n$ & -0.991 & -0.134 & 0.097 & 0.392 & - \\
\hline$p$ & -0.960 & -0.278 & 0.572 & 0.008 & $* *$ & $p$ & -0.656 & -0.755 & 0.077 & 0.459 & - \\
\hline$k$ & -0.907 & -0.421 & 0.434 & 0.028 & $*$ & $k$ & -0.904 & -0.427 & 0.103 & 0.366 & - \\
\hline fung & -0.909 & -0.417 & 0.442 & 0.025 & $*$ & fung & -1.000 & 0.022 & 0.045 & 0.655 & - \\
\hline$Z n$ & 0.909 & 0.417 & 0.442 & 0.025 & $*$ & $Z n$ & 1.000 & -0.022 & 0.045 & 0.655 & - \\
\hline \multicolumn{6}{|c|}{ CLUSTER 3} & \multicolumn{6}{|c|}{ CLUSTER 4} \\
\hline Factors & PC1 & PC2 & $\mathrm{r} 2$ & $\operatorname{Pr}(>r)$ & Sig. & Factors & PC1 & $\mathrm{PC} 2$ & r2 & $\operatorname{Pr}(>\mathrm{r})$ & Sig. \\
\hline temp & 0.995 & 0.104 & 0.391 & 0.146 & & temp & -0.753 & -0.658 & 0.757 & 0.091 & - \\
\hline prep & -0.995 & -0.104 & 0.391 & 0.146 & & prep & 0.753 & 0.658 & 0.757 & 0.091 & - \\
\hline$n$ & -0.812 & -0.584 & 0.537 & 0.047 & $*$ & $n$ & & & & & \\
\hline$p$ & -0.812 & -0.584 & 0.537 & 0.047 & $*$ & $p$ & & & & & \\
\hline$k$ & -0.812 & -0.584 & 0.537 & 0.047 & $*$ & $k$ & & & & & \\
\hline fung & 0.812 & 0.584 & 0.537 & 0.047 & $*$ & fung & & & & & \\
\hline$Z n$ & -0.812 & -0.584 & 0.537 & 0.047 & * & $Z n$ & & & & & \\
\hline \multicolumn{12}{|c|}{ CLUSTER 5} \\
\hline Factors & PC1 & PC2 & $\mathrm{r} 2$ & $\overline{\operatorname{Pr}(>r)}$ & Sig. & \multirow{2}{*}{\multicolumn{6}{|c|}{ - not significant }} \\
\hline temp & 0.330 & 0.944 & 0.654 & 0.001 & $* * *$ & \multirow{3}{*}{\multicolumn{6}{|c|}{$\mathrm{p}<0.05 * \circ$}} \\
\hline prep & -0.330 & -0.944 & 0.654 & 0.001 & $* * *$ & & & & & & \\
\hline$n$ & -0.810 & 0.587 & 0.455 & 0.008 & $* *$ & & & & & & \\
\hline$p$ & -0.677 & 0.736 & 0.848 & 0.001 & $* * *$ & \multirow{2}{*}{\multicolumn{6}{|c|}{$\mathrm{p}<0.01 \quad * * \circ$}} \\
\hline$k$ & -0.771 & 0.637 & 0.990 & 0.001 & $* * *$ & & & & & & \\
\hline fung & 0.907 & -0.421 & 0.234 & 0.135 & & \multirow{2}{*}{\multicolumn{6}{|c|}{$\mathrm{p}<0.001 * * * \circ 0 \circ$}} \\
\hline$Z n$ & -0.907 & 0.421 & 0.234 & 0.135 & & & & & & & \\
\hline
\end{tabular}

The effect of ecological factors in cluster 5 is highly significant (Tab. 3), both temperature and precipitations strongly influencing towards the decrease of the intensity of colonization (Fig.2; Tab. 1). A very strong action is identified in the case of Phosphorus and Potassium, both macro-elements impacting directly the centre of the cluster. Their effect was complemented by the distinguished significant action of the Nitrogen (Fig. 2; Tab. 3 ). Although the treatments were considered to have a reduced significant individual influence (Tab. 3), when supplemented to fertilization managed to induce, in time, a destabilization over the colonization. The NPK fertilization combined with a fungicide based treatment may reduce the colonization intensity under $1.5 \%$. The same effect is provided by the Eurofertil mezocalc fertilization, mixed with a Zinc Sulphate treatment, for both experimental years (Tab. 1).

\section{CONCLUSION}

The ecological factors established the distribution of experimental variants in clusters, through defining variation intervals of the mycorrhizal colonization parameters.

The quantum of intensity and frequency of colonization is affected in a small manner by the individual action of technological factors, their influence becoming stronger only in combined actions.

The combined action of phosphorus and potassium with the applied treatments may determine colonization frequencies of over $80 \%$ and intensities of maximum $10 \%$, noticed at the variants included in cluster 1 .

The development of a complex fertilization and treatment network, adjusted to the ecological conditions, allowed the strong expression of the mycorrhizal colonization, with intensity values ranging between 10 and $20 \%$ in cluster 2 . 
A balanced fertilization, combined with treatments, enhances the colonization frequency percentage to $100 \%$, with an optimal individual indication of the technological factors.

The acute action of fertilization and climatic factors may preclude the treatments effects, maintain a reduced colonization level, feature highlighted for the cluster 5 variants.

\section{REFERENCES}

1. Bompadre MJ, Pérgola $M$, Bidondo LF, Colombo RP, Silvani VA, Pardo AG, Ocampo JA, Godeas AM (2014). Evaluation of Arbuscular Mycorrhizal Fungi Capacity to Alleviate Abiotic Stress of Olive (Olea europaea L.) Plants at Different Transplant Conditions. The Scientific World Journal, vol. 2014, doi:10.1155/2014/378950.

2. Gill AAS, Bhadoria PBS, Sadana US (2013). Effect of mycorrhizal infection on phosphorus efficiency of maize (Zea mays L.) cultivars. Proc Natl Acad Sci India Sec B 83(2):147-157.

3. Oksanen J, Blanchet FG, Kindt R, Legendre P, Minchin PR, O'Hara RB, Simpson GL, Solymos P, Stevens MHH, Wagner H (2013), Vegan: community ecology package. R package version 2.0-10.
4. R Core Team (2014). R: A language and environment for statistical computing. R Foundation for Statistical Computing, Vienna, Austria.

5. Smith SE, Read DJ (Eds.) (2008). Mycorrhizal symbiosis, $3^{\text {rd }}$ edn. Academic, Elsevier, London.

6. Stoian H V (2011). Studiul simbiozelor micoriziene în unele ecosisteme de pajişti din zona Munţilor Apuseni. Teză de doctorat - USAMV Cluj- Napoca.

7. Sun X, Su Y, Zhang Y, Wu M, Zhang Z, Pei K, Sun L, Wan S, and Liang Y (2013). Diversity of arbuscular mycorrhizal fungal spore communities and its relations to plants under increased temperature and precipitation in a natural grassland. Chinese Science Bulletin 58: 4109-4119.

8. Tuteja N, S S Gill (Eds.) (2013). Plant Acclimation to Environmental Stress, Springer.

9. Vidican R, Stoian V, Rotar I, Păcurar F (2013). The variation of mycorrhizal colonization parameters in festuca rubra under the influence of climatic factors and differentiated fertilization. Bulletin UASMV serie Agriculture 70(1):3643.

10. Watts-Williams SJ, Turney TW, Patti AF, Cavagnaro TR (2014). Uptake of zinc and phosphorus by plants is affected by zinc fertiliser material and arbuscular mycorrhizas. Plant Soil 376:165-175. 